\title{
Temporal reflections of spontaneity in homilies
}

\author{
JILL SZAWARA \\ State University of New York, Oswego, New York 19126 \\ and \\ DANIEL C. O'CONNELL \\ Saint Louis University, Saint Louis, Missouri 69103
}

\begin{abstract}
Pause and rate phenomena were examined for two levels of spontaneity in speech in a nonlaboratory setting. Speech samples were taken from two groups of homilies (sermons): those prepared and taped for radio broadcast (Group B) and those delivered live to a congregation during a weekday service (Group L). When compared with the less spontaneous Group B, the more spontaneous Group L exhibited slower speech rate, longer pauses, greater percentage of pause time, and different distribution of pauses relative to preceding and following content and function words. Pause frequency was higher, but not significantly so. Results are compared with data from studies of temporal phenomena in reading and retelling stories and in telling spontaneous narratives.
\end{abstract}

Goldman-Eisler (1968) has contended that variation in speech rate is due mainly to the proportion of time spent pausing. Unfilled pauses (UPs) of $270 \mathrm{msec}$ or longer, as part of their multideterminate function, seem to provide time for the speaker to generate speech (O'Connell \& Kowal, in press).

Studies using temporal response measures to investigate the interaction of cognition and language behavior in the context of actual, on-the-spot generation of speech, as distinct from speech production without generation (i.e., reading), have suffered from two limitations. First, "spontaneous" speech has amounted to that produced solely for the experimenter's microphone, a rather contrived situation. Second, lack of uniformity of response measures and techniques for locating and measuring UPs has prevented comparability of results even when methodologies were otherwise adequate.

The present study transcends prior work by examining speech which was functionally independent of research design and by using methodology directly comparable with that used by O'Connell and his associates (e.g., O'Connell \& Kowal, 1972, in press) in researching temporal correlates of speech under varying conditions of age, speech task, etc.

\section{METHOD}

To avert difficulties normally preventing study of totally spontaneous speech in natural settings, present samples-homilies (sermons)-were somewhat restricted, yet not limited in latitude of expression by either instructions or stimulus materials. Noise was minimized by the setting. Intrusion of extraneous variables was reduced since subjects were 20 male clerics from generally similar background, culture, and educational level, engaged in communicating a coherent message of a particular type.

Speech samples were taken from 205 - to 10-min homilies delivered at two levels of spontaneity. The Sacred Heart Radio Program supplied tapes of 10 homilies (Group B) recorded in a sound studio for use in radio broadcasts. Ten other homilies (Group L) were unobtrusively recorded while being delivered live during weekday Catholic Masses in a medium-sized chapel on the campus of St. Louis University. Group B was inferred to be less spontaneous due to constraints of time and formality imposed by the radio broadcast; Group $L$ was inferred to be more spontaneous due to live delivery in a much less formal setting.

The groups are not construed to represent extremes of a posited spontaneity dimension which ranges from completely preplanned speech to speech completely generated at the time of production. Rather, they are thought to lie between these extremes, with Group B approximating the preplanned extreme and Group $L$ the ongoing-generation extreme.

To minimize the overwhelmingly tedious task of UP analysis, each of the 20 homilies was divided into quartiles, from each of which a representative 40 - to 50 -sec segment was taken. Thus, four segments, or a total of about $3 \mathrm{~min}$ of speech, from each homily was submitted to detailed analysis.

Following O'Connell and Kowal (1972), analysis involved (1) transcribing speech in conventional orthography, (2) deriving permanent graphic records by processing aural recordings through a Brüel and Kjaer audio frequency spectrometer (Type 2112) and level recorder (Type 2305), (3) collating the two records and transcription, and (4) locating and measuring on graphic records all UPs $270 \mathrm{msec}$ or longer.

Temporal phenomena, all reported as relative measures to correct for differences in sample time or number of syllables, include speech rate (syllables/second), percentage of pause time (UP time/total time), mean pause duration (total UP duration in seconds/total number of UPs), UP duration (seconds/syllable), and UP frequency (number of UPs/syllable). Other measures were UP location relative to preceding and following content and function words (as defined by Miller, Newman, \& Friedman, 1958), and location between or within syntactic units. Vocal hesitations were not analyzed due to their infrequency in this sample.

\section{RESULTS}

Based on the expectation that the more spontaneous group (L) would exhibit slower speech rate, greater percentage of pause time, and more frequent and longer UPs than the less spontaneous group (B), one-tailed $t$ tests (Winer, 1971) were done on temporal measures. Statistically significant differences were found for all 
Table 1

Means and One-Tailed $t$ Tests of Response Measures (Winer, 1971)

\begin{tabular}{|c|c|c|c|}
\hline \multirow[b]{2}{*}{ Measure } & \multicolumn{2}{|c|}{ Mean } & \multirow[b]{2}{*}{$t(18 d f)$} \\
\hline & Group L & Group B & \\
\hline Speech Rate (syl/sec) & 3.22 & 3.45 & $11.52+$ \\
\hline Percentage UP Time & 37.9 & 29.4 & $2.20 * *$ \\
\hline Mean UP Duration (sec) & .955 & .780 & $2.04 *$ \\
\hline UP Duration (sec/syl) & .125 & .088 & $2.07 *$ \\
\hline Number UPs/syl & .128 & .111 & 1.46 \\
\hline${ }^{*} p<.05$ & $<<.025$ & & $<.0005$ \\
\hline
\end{tabular}

Table 2

UP Frequency and Mean UP Duration Relative to Location

\begin{tabular}{|c|c|c|c|c|c|c|}
\hline \multirow[b]{3}{*}{ Location } & \multicolumn{4}{|c|}{ Total UPs } & \multicolumn{2}{|c|}{$\begin{array}{l}\text { Mean UP Dura- } \\
\text { tion }(\mathrm{msec})\end{array}$} \\
\hline & \multicolumn{2}{|c|}{ Group L } & \multicolumn{2}{|c|}{ Group B } & \multirow{2}{*}{$\begin{array}{c}\text { Group } \\
\text { L }\end{array}$} & \multirow{2}{*}{$\begin{array}{c}\text { Group } \\
\text { B }\end{array}$} \\
\hline & $\mathrm{N}$ & $\%$ & $\mathrm{~N}$ & $\%$ & & \\
\hline C-UP-F & 383 & 54.0 & 457 & 66.5 & 1056 & 787 \\
\hline F-UP-F & 195 & 27.5 & 106 & 15.5 & 921 & 789 \\
\hline C-UP-C & 54 & 7.5 & 99 & 14.5 & 788 & 762 \\
\hline F-UP-C & 76 & 11.0 & 25 & 3.5 & 626 & 784 \\
\hline
\end{tabular}

measures except UP frequency (see Table 1).

Of all words in the samples, $62 \%$ were function words $(\mathrm{L}=65 \%, \mathrm{~B}=59 \%)$ and $38 \%$ were content words $(\mathrm{L}=35 \%$, $\mathrm{B}=41 \%$ ). Pauses were located relative to preceding and following content and function words, so that UP locations were categorized as C-UP-C, F-UP-F, C-UP-F, or F-UP-C. The chi square (Young \& Veldman, 1965) derived from the proportion of UPs in each location was significant $(72.07, \mathrm{p}<.01)$. The greatest proportion of UPs occurred after a content word and before a function word for each group; $82 \%$ of all UPs occurred before function words (see Table 2). Perhaps of more importance is the finding that mean UP duration varied greatly with location for Group L, while remaining remarkably consistent across location for Group B.

A significant difference was found between groups on proportion of UPs within syntactic units $[\mathrm{t}(18)=5.80$, $\mathrm{p}<.005$ ], even though such proportions were small for both groups $(\mathrm{L}=17.8 \%, \mathrm{~B}=6.5 \%)$. This finding should be viewed with extreme caution, however, in light of Martin and Strange's (1968) warning that "so much can be deleted in natural speech...because it is unnecessary or 'understood,' that it is hazardous to guess at the exact constituent structure of any given utterance" (p. 478).

\section{DISCUSSION}

Results for all measures except UP frequency were very much in keeping with expectations generated from previous studies of relative spontaneity. Expected differences between Groups L and $B$ were found. In addition, the speculation that these groups would display temporal values between the two extremes of the spontaneity dimension seems to be supported by comparison with findings from other research which has applied identical methodology in studying different speech tasks (representing differing levels of spontaneity). Table 3 lists data from top to bottom in assumed order of increasing spontaneity. Retellings of read stories are listed separately at the bottom because spontaneity level is not clear.

Speech rate, one of the more sensitive temporal measures, shows an orderly decrease as the demands of speech generation increase. Inversely, UP duration increases in an orderly fashion. The same is true of percentage of UP time.

Pause frequency measures are not so orderly and seem here to distinguish only grossly between reading and nonreading. In addition, overall differences between present Group $L$ and the spontaneous narratives seem to be quite small.

While retellings are clearly distinct from readings, as reported in the literature, discrepancies between retellings of different stories make interpretation difficult in the present context. Child story data fall largely between readings and Group B, as might be expected, since retellings are based on a verbal model. Dentist story data, on the contrary, fall neatly in line at the bottom of Table 3 , perhaps due to differences in ease of recall between child and dentist stories. Because different groups of subjects read and retold the two stories, the data may reflect individual differences as well.

It may be wise for pause researchers to move in the direction of examining individual differences in more detail, perhaps by studying how temporal patterns of a given speaker change within a speech situation and between different types of speech situations. Increased study of speech in more natural settings, especi-

Table 3

Adult Male Subjects From Three Studies Compared on Six Measures

\begin{tabular}{|c|c|c|c|c|c|c|}
\hline \multirow[b]{2}{*}{ Speech Task } & \multicolumn{2}{|c|}{ Frequency Measures } & \multicolumn{2}{|c|}{ Duration Measures } & \multicolumn{2}{|c|}{ Overall Measures } \\
\hline & $\begin{array}{c}\text { N of UPs/ } \\
100 \mathrm{syl}\end{array}$ & $\mathrm{N}$ of syl/UP & $\begin{array}{r}\text { M Length } \\
\text { UP (msec) }\end{array}$ & $\begin{array}{l}\text { Total UP Time } \\
(\mathrm{sec}) / 100 \mathrm{syl}\end{array}$ & syl/sec & $\begin{array}{c}\text { Percentage } \\
\text { UP Time }\end{array}$ \\
\hline $\begin{array}{l}\text { Dentist Reading* } \\
\text { Child Reading* } \\
\text { Group B** } \\
\text { Group L** } \\
\text { Narratives } \dagger\end{array}$ & $\begin{array}{r}6.6 \\
8.3 \\
11.1 \\
12.8 \\
12.1\end{array}$ & $\begin{array}{r}16.43 \\
12.88 \\
9.42 \\
8.25 \\
8.84\end{array}$ & $\begin{array}{l}696 \\
649 \\
780 \\
955 \\
992\end{array}$ & $\begin{array}{r}4.9 \\
5.1 \\
8.8 \\
12.5 \\
13.1\end{array}$ & $\begin{array}{l}4.28 \\
4.12 \\
3.45 \\
3.22 \\
3.15\end{array}$ & $\begin{array}{l}18.2 \\
20.1 \\
29.4 \\
37.9 \\
34.7\end{array}$ \\
\hline $\begin{array}{l}\text { Dentist Retelling* } \\
\text { Child Retelling* }\end{array}$ & $\begin{array}{l}15.7 \\
10.2\end{array}$ & $\begin{array}{l}7.05 \\
9.85\end{array}$ & $\begin{array}{r}1123 \\
858\end{array}$ & $\begin{array}{r}19.1 \\
8.8\end{array}$ & $\begin{array}{l}2.46 \\
3.65\end{array}$ & $\begin{array}{l}40.3 \\
28.2\end{array}$ \\
\hline
\end{tabular}

*Clemmer (1976), normal males, ordinary versions of stories; data obtained by personal communication, November $11,1976$. **Present study.

tSabin, E. J., O'Connell, D. C., \& Kowal, S. Developmental aspects of pause and rate phenomena. Paper presented at the meeting of the Psychonomic Society, St. Louis, November 1976. Combined means of 21-and 49-year-old male groups; data obtained by personal communication, November 12, 1976. 
ally dialogues and multilogues, would seem to be called for. Finally, consistent methodology is necessary if knowledge is to be expanded through accumulating data which can be compared.

\section{REFERENCES}

Clemmer, E. J. Linguistic and cognitive aspects of speech hesitations in schizophrenics and normals (Doctoral dissertation, Saint Lou is University, 1975). Dissertation Abstracts International, 1976, 36, 3135B-3685B. (University Microfilms No. 76-857, 160).

Goldman-EIsLeR, F. Psycholinguistics: Experiments in spontaneous speech. London: Academic Press, 1968.

Martin, J. G., \& Strange, W. Determinants of hesitations in spontaneous speech. Journal of Experimental Psychology, 1968, 76, 474-479.
Miller, G. A., Newman, E. B., \& Friedman, A. E. Lengthfrequency statistics for written English. Information and Control, 1958, 1, 370-398.

O'Connell, D. C., \& Kowal, S. Cross-linguistic pause and rate phenomena in adults and adolescents. Journal of Psycholinguistic Research, 1972, 1, 155-164.

O'Connell, D. C., \& Kowal, S. Pausology. In W. Sedelow \& S. Sedelow (Eds.), Computer uses in the study of language: Cognitive approaches (Vol. 3). The Hague: Mouton, in press.

WINER, B. J. Statistical principles in experimental design. New York: McGraw-Hill, 1971.

YounG, R. K., \& VELDMAN, D. J. Introductory statistics for the behavioral sciences. New York: Holt, Rinehart, \& Winston, 1965.

(Received for publication December 23, 1976.) 